\title{
Effects of probiotic supplements on growth performance and intestinal microbiota of partridge shank broiler chicks
}

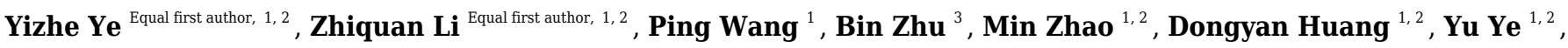 \\ Zhen Ding $^{1,2}$, Longrui Li ${ }^{4}$, Gen Wan ${ }^{1,2}$, Qiong Wu ${ }^{1,2}$, Deping Song ${ }^{\text {Corresp., }{ }^{1,2}, \text { Yuxin Tang }}{ }^{1,2}$ \\ ${ }^{1}$ Department of Preventive Veterinary Medicine, College of Animal Science and Technology, Jiangxi Agricultural University, Nanchang, China \\ 2 Jiangxi Engineering Research Center for Animal Health Products, Jiangxi Agricultural University, Nanchang, China \\ 3 Jiangxi Red animal health products Co., LTD., Nanchang, China \\ 4 Jiangxi Newtoldhow animal pharmaceutical Co., LTD, Ji'an, China \\ Corresponding Author: Deping Song \\ Email address: sdp8701@jxau.edu.cn
}

Background $\square$ The benefits of probiotics being used in animals are well-documented via evidenced growth performance improvement and positive modulations of gut microbiota (GM). Thus, a combination of effective microorganisms (EM) has been frequently used in animal production, including broilers. However, there are only very limited reports of EM on the growth performance and the modulation in GM of partridge shank broiler chicks. Methods: We attempted to evaluate the effects of a basal diet with the addition of an EM mixture on the growth performance and gut microbiome of the chicks. A total of 100 tenday-old female partridge shank broiler chicks were randomly divided into two groups of 50 chicks each, of which, one group fed with EM supplementation in the basal diet (designated as EM-treated group), the other group just fed with a basal diet (referred as to non-EM treated group or control group). The body weight, daily feed intake, daily gain, feed conversion ratio and other growth parameters were observed and compared between EM-treated and non-EM-treated chicks, and the gut microbiota was profiled by 16S rRNA based next generation sequencing (NGS). Results $\square$ Chicks fed with a basal diet with the addition of EM showed significantly increased performances in body weight (BW), average daily gain (ADG) and reduced feed conversion ratio (FCR). Histological observation indicated that dietary supplementation of EM significantly increased the villus heights (VH) and the ratio of villus height to crypt depth $(\mathrm{VH} / \mathrm{CD})$, while decreased the $\mathrm{CD}$ of jejunum, ilea, and ceca. The results of 16S rRNA -based gut microbiota analyses showed that Firmicutes accounted for the most of the relative abundance $(63.24 \% \sim 92.63 \%)$, followed by Proteobacteria (0.62\% 23.94\%), Bacteroidetes (0.80\% 7.85\%), Actinobacteria $(0.06 \% \sim 13.69 \%)$ and others in both EM-treated and non-EM-treated broiler chicks. The addition of EM could not alter the alpha diversity of gut microbiota. Compared with the non-EM-treated chicks, the abundances of bad bacteria in the phyla of Firmicutes, 
Euryarchaeota, and Ruminococcus were dramatically decreased in that of EM-treated chicks, while the abundances of good bacteria in the phyla of Actinobacteria and WPS-2 were significantly increased. Conclusions: The supplementation of EM in feed could improve the growth performance and positively influence the morphological characteristics of the intestine, and ameliorate the community and structure of the intestinal microbiota of partridge shank broiler chicks. 
1 Article

2 Effects of probiotic supplements on growth performance and gut

3 microbiota of partridge shank broiler chicks

4 Yizhe Ye ${ }^{1,2, \dagger}$, Zhiquan $\mathrm{Li}^{1,2, \dagger}$, Ping Wang ${ }^{1,2}$, Bin Zhu ${ }^{3}$, Min Zhao ${ }^{1,2}$, Dongyan Huang ${ }^{1,2}$,

5 Yu Ye ${ }^{1,2}$, Zhen Ding ${ }^{1,2}$, Longrui Li ${ }^{4}$, Gen Wan ${ }^{1,2}$, Qiong Wu ${ }^{1,2}$, Deping Song1, 2, *, Yuxin

6 Tang 1,2

7

8 Short title: Effects of probiotics on partridge shank broilers

9

${ }^{1}$ Department of Preventive Veterinary Medicine, College of Animal Science and Technology,

11 Jiangxi Agricultural University, Nanchang, Jiangxi, 330045 China

$12{ }^{2}$ Jiangxi Engineering Research Center for Animal Health Products, Jiangxi Agricultural

13 University, Nanchang, Jiangxi, 330045 China

$14{ }^{3}$ Jiangxi Red Animal Health Products Co., LTD., Nanchang, Jiangxi, 331700 China

$15{ }^{4}$ Jiangxi Newtoldhow Animal Pharmaceutical Co., LTD., Ji'an, Jiangxi, 331409 China

$17 \dagger$ These authors contributed equally to this study.

$18 *$ Corresponding author:

19 Deping Song

201101 Zhimin Dadao, Nanchang, Jiangxi Province, 330045, China

21 Email address: sdp8701@jxau.edu.cn 


\section{ABSTRACT}

23 Background: The benefits of probiotics being used in animals are well-documented via

evidenced growth performance improvement and positive modulations of gut microbiota (GM).

Thus, a combination of effective microorganisms (EM) has been frequently used in animal

production, including broilers. However, there are only very limited reports of EM on the growth performance and the modulation in GM of partridge shank broiler chicks. This study aimed to assess the effects of a basal diet with the addition of an EM mixture (84\% of Lactobacillus) on the growth performance, intestinal histomorphology and microbiome of the chicks.

Methods: A total of 100 ten-day-old female partridge shank broiler chicks were randomly

divided into two groups of 50 chicks each, of which, one group was fed with EM

supplementation in the basal diet (designated as EM-treated group), the other group was just fed

with a basal diet (referred as to non-EM treated group or control group). The body weight, daily

feed intake, daily gain, feed conversion ratio and other growth parameters along with intestinal

histomorphology were observed and compared between EM-treated and non-EM-treated chicks, and the gut microbiota was profiled by $16 \mathrm{~S}$ rRNA -based next generation sequencing (NGS) during experimental periods.

Results: Chicks fed with a basal diet with the addition of EM showed significantly increased performances in body weight (BW), and average daily gain (ADG), but reduced feed conversion ratio (FCR). Histological observation indicated that dietary supplementation of EM significantly increased the villus heights $(\mathrm{VH})$ and decreased the crypt depth $(\mathrm{CD})$ of jejunum, ilea, and ceca, and thus increased the ratio of villus height to crypt depth (VH/CD). The results of 16S rRNA - 
43 based gut microbiota analyses showed that Firmicutes accounted for the most of the relative

44 abundance (63.24\% 92.63\%), followed by Proteobacteria (0.62\% 23.94\%), Bacteroidetes

$45(0.80 \% \sim 7.85 \%)$, Actinobacteria $(0.06 \% \sim 13.69 \%)$ and the others in both EM-treated and non-

46 EM-treated broiler chicks. The addition of EM could not alter the alpha diversity of gut

47 microbiota. Compared with the non-EM-treated chicks, the abundances of bad bacteria in the phyla of Firmicutes, Euryarchaeota, and Ruminococcus were dramatically decreased in that of

49 EM-treated chicks, while the abundances of good bacteria in the phyla of Actinobacteria and WPS-2 were significantly increased.

51 Conclusions: The supplementation of the EM in feed could improve the growth performance and positively influence the histomorphological characteristics of the intestine, and ameliorate the community and structure of the intestinal microbiota of partridge shank broiler chicks.

Subjects: Food Science and Technology, Zoology, Microbiology

Keywords: Probiotics; Effective Microorganisms; Growth Performance; Microbiota; Partridge

Shank Broiler

57

\section{INTRODUCTION}

59 Feed cost accounts for about $70 \% \sim 80 \%$ of the total cost of poultry production. Thus, great

60 efforts have been made to improve the nutritive values of feeds to enhance growth performance

61 and health of animals (Ahmad et al., 2018). Probiotics, defined as "live microorganisms", are

62 one of the major feed additives routinely being used in animal production for decades due to the conferred health benefits to the host when administered in an adequate amount (FAO, 2002; 
64 Markowiak et al., 2018, Iriti et al., 2019; Reszka et al., 2020). For poultry, probiotics could

65

66

67

improve feed intake and digestion efficiency by increasing the activity of digestive enzymes,

keep the balance of bacteria in gastrointestinal (GI) tract, promote the gut integrity and thus improve the growth performance and health of birds (Johnson et al., 2018; Soomro et al., 2019;

Hack et al, 2020). Patidar et al. (1999) showed that Lactobacilli on increased the titers of hemagglutination inhibition antibodies of chicks after feeding for 3-4 weeks. Vinayasree et al. (2012) evaluated the effect of probiotic organisms on the performance of broilers, and found with the use of probiotics fecal coliform bacteria counted at the end of 6th week in experiment group were significantly lower when compared to the control groups. Fazelnia et al. (2021) showed that the dietary supplementation of potential probiotics Bacillus subtilis, Bacillus licheniformis, and Saccharomyces cerevisiae and synbiotic improved the growth performance and immune responses of broiler chicks. Additionally, supplementation of synbiotic and probiotic alleviated the negative effects of S. typhimurium on growth and immunity of broiler chicks. Also other studies have reported beneficial effects of different probiotics on the broiler growth (Zuanon et al., 1998; Ergun et al., 2000; Vicente et al., 2007).

In 1991, Terou Higa reported a multifunctional microbe flora composed of more than 80 kinds of microorganisms, named as Effective Microorganisms (EM) (Higa., 1991; Aruoma et al., 2002). The dominant bacteria in the EM are Lactobacillus, photosynthetic bacteria, Actinomycetes, yeasts and filamentous bacteria. Nowadays, EM has been widely used in more than 40 countries and/or areas, including Japan, the United States, India and China (Rybarczyk et al., 2016; Li et al., 1994). Previous studies demonstrated that EM can also improve soil 
85

86

87

performance, promoting crop growth and enhancing plant stress resistance. Investigations on broilers carried out by Chantsawang et al. (1999) showed that EM could increase body weight, feed intake, feed conversion efficiency, and immune response of EM-treated chicks. Safalaoh et al. (2006) conducted a study on the effect of EM on body weight gain, dressing percentage, abdominal fat and serum cholesterol content of broilers by supplementing EM in drinking water, and it was found that birds fed with EM had higher weight gains, feed efficiency, while lower feed intake and serum cholesterol content than that in control birds. Besides, EM also has a beneficial effect on promoting animal growth and health. Further studies showed that EM could also improve meat quality, increase slaughter rate, and reduce the rate of death in economic animals (Jagdish et al., 1993; Alvarez et al., 1994; Silva et al., 2000; Patterson et al., 2003; Alagawany et al., 2018; Abd et al., 2020). In contrast, some research results reported that the supplementation of EM in chicken's feed had no significant effect on mortality, feed conversion ratio (FCR) and weight gain (Wondmeneh et al., 2011).

Partridge shank chick, a local broiler breed in China, is a relatively smaller body size chick with the features of tender meat and high nutritional value as well as a special flavor when cooked. Therefore, it is very well favored by consumers in China. According to the previous reports, local breeds of broiler chick account for $46.52 \%$ of broiler meat in China in 2017 , and this proportion was continuously increased in 2018 (Zhao et al., 2019). However, the growth rate of partridge shank broiler chick is slow. This characteristic may attribute to its genetic basis, the environmental factor(s), nutrition, and so on. The gut of animals is important site of nutrient absorption in animals, and better development of the intestinal system could benefit the nutrient 
106

107

108

109

110

111

112

113

114

115

116

117

118

119

120

121

122

123

124

125

absorption and improve animal growth performance and health (Mekbungwan et al., 2004).

However, the information regarding the development of intestinal histomorphology and gut microbiota of partridge shank broiler chicks is roughly unknown, and so does the knowledge on the effect of EM on the growth performance of the broilers. We hypothesized that the EM would improve the growth performance and the structure and composition of gut microbiota, perhaps via a mechanism of inhibiting the colonization of bad bacteria. The aim of the study was to evaluate the effects of EM on the growth performance, intestinal gut health and gut microbiota of partridge shank broilers.

\section{MATERIALS AND METHODS}

\section{Ethics Statement}

All procedures involving live animals were verified and approved by the Office of Animal Care and Use of Jiangxi Agricultural University (protocol number JXAU-LL-20190022). The chicks used in this study were housed at the Animal Research Unit of Jiangxi Agricultural University, located at the college of Animal Science and Technology in Nanchang, Jiangxi, China.

\section{Chicks and experimental design}

Ten-day-old female partridge shank broiler chicks $(n=100)$ were purchased from a local commercial hatchery. All of the chicks had been individually wing-tagged, and immunized with the vaccines against Marek's disease, Newcastle disease, and Infectious bursal disease at 1, 4 and 10 days old, respectively. The experiment was carried out for a 20-day period starting in Jan, 
2020. All broiler chicks had ad libitum access to feed and water, and the feed was offered four

127 times daily at $06.00 \mathrm{am}, 11.00 \mathrm{am}, 16.00 \mathrm{pm}$, and $20.00 \mathrm{pm}$, respectively. The chicks were then

randomly divided into two experimental groups, and each group included 5 repetitions with 10

chicks per replication. All chicks of each replication were housed in $0.96 \times 0.96 \mathrm{~m}$ chick coops

(at the Chicken Experimental Unit, no. 109, Jiangxi Agricultural University, China) under the

same environmental conditions, including a constant temperature of 28 to $31^{\circ} \mathrm{C}$ and $20 \mathrm{~h}$ daily

lighting access throughout the experiment.

The nutrient levels of the basal diet (maize-soybean-based meal diet) corresponded to the

NRC (1994) recommended requirements for broilers (Table 1). The EM suspensions used in this study was generously provided by Prof. Nanhui Chen (Department of Preventive Veterinary

Medicine, Jiangxi Agricultural University, China). Chickens in experimental group, designated as EM-treated group (abbreviated as group EM), were fed a basal diet supplemented with $0.5 \mathrm{ml}$ (about $2.5 \times 10^{9}$ colony-forming unit) EM per chick/day for 20 days and the chicks in the negative control group, designated as non-EM-treated group (abbreviated as group B) were just fed by the basal diet for 20 days. The bacterial composition of the EM used in this study was determined by $16 \mathrm{~S}$ rRNA sequencing on Illumina HiSeq 4000 platform, and the bacterial background information of EM used is supplied in Supplementary Table S1. The initial and final weights, daily feed intake of the chicks in each group were recorded, and the feces of five chicks in each group were sampled at the $1^{\text {st }}, 10$ th, and 20 th experimental day. Then the feed intake was daily measured, body weight (BW) gain was measured at the end of experiment and then the data were used to calculate average daily intake (ADFI), average daily gain (ADG), and feed/gain 
147 ratio $(\mathrm{F} / \mathrm{G})$. At the 20th experimental day, 5 chicks of each group were euthanized by

148 pentobarbital sodium and dissected, and the intestinal tissues and cecal contents were collected.

149 For gut microbiota profiling, excreta at the $1^{\text {st }}, 10$ th and 20 th experimental day and cecal

150 contents at the 20th experimental day were collected in both groups (designated as EM0, EM10,

151 EM20, and EM20C for samples from EM-treated chicks; and B0, B10, B20, and B20C for

152 samples from non-EM-treated chicks).

153

\section{Histomorphology observation}

At necropsy, different sections of intestines were examined and collected for histological observation according the previous methods in our lab (Zhang et al, 2020). For each tissue section, at least ten villi and crypts were measured using the cellSens Standard system (Olympus, Japan) with villous height (VH) and crypt depth (CD), which would be used for the calculation of $\mathrm{VH} / \mathrm{CD}$ ratio.

\section{Bacterial DNA extraction and 16S rRNA gene sequencing}

Bacterial genomic DNA were extracted by the QIAamp DNA Stool Mini Kit (Qiagen, Hilden, Germany) and quantified according to the previous method (Song et al., 2017).

Amplification of the hypervariable V4 region of 16S rRNA gene was performed by using 'universal' primers 515F (5'-GTGYCAGCMGCCGCGTAA-3') and 806R (5'-

GGACTACNVGGGTWTCTAA-3') flanked with adapter and barcode sequences (Kuczynski et al., 2011). The PCR was carried out under the following conditions: $95^{\circ} \mathrm{C}$ for $5 \mathrm{~min} ; 25$ cycles of: $95^{\circ} \mathrm{C}$ for $30 \mathrm{~s}, 56^{\circ} \mathrm{C}$ for $45 \mathrm{~s}, 72^{\circ} \mathrm{C}$ for $30 \mathrm{~s}$; a final extension of $72^{\circ} \mathrm{C}$ for $10 \mathrm{~min}$, and then hold at 
$1674^{\circ} \mathrm{C}$. The amplicons were cleaned by using AMPure XP beads (Beckman Coulter, Brea, CA, 168 USA), and then normalized, pooled with the adapters and the dual indices using the Nextera XT 169 Index Kit (Cat No.: FC-131-2001, Illumina, San Diego, CA, USA). A second PCR amplification 170 with 5 cycles were executed with Nextera XT Index primers in following conditions: $95^{\circ} \mathrm{C}$ for 4 $171 \min ; 5$ cycles of: $95^{\circ} \mathrm{C}$ for $30 \mathrm{~s}, 55^{\circ} \mathrm{C}$ for $40 \mathrm{~s}, 72^{\circ} \mathrm{C}$ for $40 \mathrm{~s}$; a final extension of $72^{\circ} \mathrm{C}$ for $5 \mathrm{~min}$, 172 and then hold at $4^{\circ} \mathrm{C}$. The PCR products were cleaned up again with AMPure XP beads, and thus 173 the sequencing libraries were established. The libraries were validated to the expected size of 174 about $440 \mathrm{bp}$ on a Bioanalyzer trace for the final library. The libraries were quantified using a 175 Qubit 4.0 Fluorometer (Thermo Fisher Scientific, Waltham, MA, USA) according to the fluorometric quantification method using dsDNA binding dyes. The concentration of each DNA 177 library was determined by an Agilent Technologies 2100 Bioanalyzer. For sequencing, the individual library was diluted for $4 \mathrm{nM}$, and aliquoted with $5 \mu$ of diluted DNA, then pooled and sequenced on the Illumina Hiseq 4000 platform in paired-end (PE) technology at $2 \times 250 \mathrm{nt}$ using Illumina v2 kit (Illumina, San Diego, CA, USA) in Guhe Information Co., Ltd in Hanzhou, 181 China.

\section{Metagenomic analysis}

The raw reads from $16 \mathrm{~S}$ rRNA sequencing were automatically input for quality control, trimming, demultiplexing of samples and then generated fastq output files. Afterwards, the reads were subjected to further proceeding by pipeline QIIME 2 (http://qiime.org/). Operational taxonomic units (OTUs), included de-replication, cluster, detection of chimera, were picked 
187 188 189 190

using Vsearch v1.11.1 based on a 97\% 16S rRNA gene sequence identity level (Rognes et al., 2016). Taxonomic assignment of individual datasets was determined at several taxonomic levels: kingdom, phylum, class, order, family, genus, and species by using SILVA 128 (Quast et al., 2013). OTUs classified as chloroplasts or mitochondria were subsequently removed. The obtained sequences classified as bacteria and archaea were examined with BLAST (Basic Local Alignment Search Tool) (Mount, 2007).

Alpha diversity was calculated with QIIME, including index of observed species, chao1, shannon, simpson, and PD_whole_tree. Beta diversity was determined by using QIIME with the matrix of weighted and unweighted Unifrac distance. LEfSe analysis was performed by using linear discriminant analysis (LDA) to estimate the different size of the effect of abundance of each component (species), and to identify communities or species that had significant differences in the classification of the samples (Segata et al., 2011).

\section{Statistical analysis}

The differences of data between EM-treated group and non-EM-treated group were analyzed by student $t$ test in SPSS 26.0 (IBM, USA). The replicate was defined as the experimental unit. Comparisons of parameters of growth performance across the groups were carried out by oneway analysis of variance (ANOVA) and significant differences among group means were determined using the least significant difference (LSD) test. The beta diversity indices were calculated based on the principal co-ordinates analysis (PCoA) method (Quinn Gp, 2002). Kruskal-Walls test was used to identify the difference of alpha diversity indices and bacterial 
207 species which showed significant differences between different groups by R stats package. A p-

208 value of $<0.05$ was set as the statistically significant level.

209

210

\section{RESULTS}

211

212

213

214

215

216

217

218

219

220

221

222

223

224

225

\section{Effects of EM on growth performance of partridge shank broiler chicks}

In this study, the diet with the addition of EM significantly increased the BW, ADG and decreased the FCR at the 10th $(P<0.001)$ and 20th $(P<0.05)$ day of the experiment when compared with the controls (Table 2). The BW gain for all the evaluated periods (day 1 to 10 , day 1 to 20) was improved for chicks supplemented with EM. Similarly, ADG from day 1 to 10, from day 11 to 20 and overall period (day 1 to 20) were increased in EM-treated chicks.

Moreover, FCR was decreased during day 1 to 10 , and day 11 to 20, while no significance difference in all evaluated period. The EM addition did no significant impact on ADFI.

\section{Effects of EM on the histomorphology of intestines of partridge shank broiler chicks}

Diet with the supplementation of EM significantly increased the jejunal villus height $(P<0.001)$, but decreased the jejunal crypt depth $(\mathrm{CD})(P<0.001)$, and thus increased the ratio of jejunal villus height to crypt depth $(\mathrm{VH} / \mathrm{CD}, P<0.001)$ but decreased the jejunal crypt depth $(P<$ 0.001). Furthermore, EM supplementation remarkably increased both ileal $(P<0.001)$ and cecal $(P<0.001)$ villus height and the ratio of VH/CD $(P<0.001)$, but decreased ileal $(P<0.05)$ and cecal $(P<0.05)$ crypt depth (Table 3$)$. 
227 The samples $(n=40)$ were sequenced on an Illumina HiSeq 4000 platform and a total of

$2283,505,030$ raw sequence reads were generated. After quality control, 3,234,992 (92.30\%) clean

229 reads were obtained, with an average of 80,874 clean sequences per sample (supplementary

230 Table S2). Shannon, Simpson and Chao1 indices were employed to evaluate the alpha diversity

231 within the sequence datasets based on the observed OTUs. Of the alpha diversity indices, no

232 significant variation was observed between the comparable groups B0/EM0, B10/EM10,

233 B20/EM20, and B20C/EM20C, indicating EM had limited influence on the alpha diversity

234 indices (Table 4). The beta diversity among groups was presented on principal co-ordinates

235 analysis (PCoA) to distinguish the microbial communities (Figure 1). The results revealed that

236 the microbial communities in cecal contents showed a striking distinctness with that in excreta.

237 Clusters of excreta microbiota were superimposed over the PCoA analysis and represented the

238 differences among the groups.

239

240

241

242

243

244

245

246

\section{Comparison of microbial communities of excreta microbiota between EM-treated and non-}

\section{EM-treated chicks}

In the composition analysis at the phylum level, Firmicutes accounted for the most of the relative abundance (63.24\% 92.63\%), followed by Proteobacteria (0.62\% 23.94\%), Bacteroidetes

$(0.80 \% \sim 7.85 \%)$, Actinobacteria $(0.06 \% \sim 13.69 \%)$ and others. With increasing age, the abundance of Firmicutes tended to decrease and the abundance of Proteobacteria, Bacteroidetes and Actinomycete tended to increase (Figure 2 and Table S3). At the genus level, Lactobacillus had the highest relative abundance in the excreta samples (33.26\% 78.03\%), followed by 
247 Streptococcus (0.01\% 19.07\%), Enterococcus (0.16\% 20.94\%), and Bacteroides

$248(0.46 \% \sim 5.27 \%)$. Similarly, the abundances of Lactobacillus in feces in both EM-treated and non-

249 EM-treated broiler chicks were reduced, while the abundances in EM-treated chicks were higher 250 than that in non-EM-treatedled chicks. However, in cecum samples, an unclassified genus from

251 the family Lachnospiraceae accounted for the most of the relative abundance $(24.02 \% \sim 36.41 \%)$,

252 followed by unclassified genus from the order Clostridiales $(20.32 \% \sim 23.40 \%)$, unclassified

253 genus in the family Lachnospiraceae (6.50\% 7.30\%), and Ruminococcus $(2.82 \% \sim 4.63 \%)$

254 (Figure 3 and Table S4).

\section{Gut microbiota landscape of non-EM-treated chicks}

256 To explore the gut microbiota landscape of the boiler chicks in non-EM-treated group, ANOVA

257 test was performed. At the phylum level, the abundances of Firmicutes were significantly

258 decreased $(90.53 \%$ to $63.24 \%)$ from B0 (10d age) to B20 (30d age). While the abundances of

259 Euryarchaeota, Synergistetes, Verrucomicrobia, and Actinobacteria were significantly increased

260 as the chicks grew up (Table 5 and Figure S1A). At the genus level, abundances of Prevotella,

261 Coprococcus, Desulfovibrio, Gallibacterium, and Acinetobacter tended to be increased from age

262 10d to 30d (Figure S1B).

263 Gut microbiota landscape of EM-treated chicks

264 Among the EM-treated partridge shank broiler chicks, four kinds of gut bacteria at the phylum

265 level were significantly different among growth stages of EM0, EM10 and EM20. Bacteria in

266 Proteobacteria, Synergistetes, and WPS-2 were significantly increased from EM0 to EM20 
267 (Table 6 and Figure S2A). At the genus level, the abundances of Methanobrevibacter,

268 Enterococcus, Streptococcus, and Gallibacterium were significantly augmented in EM10, while

269 decreased in EM20. The abundances of Faecalibacterium and Megamonas were reduced during

270 the time of EM supplementation (Figure S2B).

\section{Comparison of excretal and cecal microbiota between EM-treated and non-EM-treated}

272 chicks

273 To address the impacts of EM on the structure and abundance of microbiota in feces and cecal

274 contents, the abundances of fecal and cecal bacteria in chicks at the end of the experiment were

275 analyzed. For the excretal microbiota, the abundances of two bacteria $\operatorname{TM7}(P<0.01)$ and

276 Tenericutes $(P<0.01)$ at the phylum level and one at the genus level Acinetobacte $(\mathrm{P}<0.05)$

277 were reduced in group EM20 when compared with that in group B20 (Table 7 and Figure S3).

278 As the normal structure of bacterial communities in ceca was very different from that in excreta,

279 the changes of cecal microbiota in EM-treated broiler chicks were different. When compared

280 with the control group, the abundances of Firmicutes $(P<0.001)$, Euryarchaeota $(P<0.05)$, and

281 Ruminococcus $(P<0.05)$ were significantly reduced, while the abundances of Actinobacteria $(\mathrm{P}$

$282<0.001)$ and WPS-2 $(P<0.001)$ were significantly increased (Table 8 and Figure S4).

\section{DISCUSSION}

As reported from previous studies, probiotics supplements with probiotics in feed could improve 
287 the feed intake, weight gain and feed efficiency in broilers (Waititu et al., 2014; Qorbanpour et 288 al., 2018; Jha et al., 2020). Therefore, in order to enhance the growth rate, maintain intestinal integrity, and improve the overall health status of birds in intensive production conditions, the use of probiotic preparations as a supplement is a common practice in poultry production (Wondmeneh et al., 2011). In this study, an EM mixture containing multiple species of bacteria, of which most are naturally existing beneficial microorganisms, including both oxybiotic and anaerobic microbes, was applied to evaluate the effects on the growth performance, intestinal histomorphology, and gut microbiota of partridge shank broiler chicks. Researchers have reported that probiotics had positive effects on BW and ADG of animals (Huang et al., 2019; Tao et al., 2021). The functional inconsistency of probiotics among these studies, including the present study, might attribute to the type and dosage of probiotics being used, and the breeds of the broilers as well.

In this study, positive effects of the EM supplementation on BW, ADG and FCR were found in partridge shank broiler chicks. The BW gain and ADG were significantly higher in EM-fed chicks than that in control chicks both at the first phase $\left(0-10^{\text {th }}\right.$ day) and the second phase (11$20^{\text {th }}$ day) of the experiment. However, the ADFI showed no difference between the EM-fed and non-EM-treated control chicks in both phases, which indicated that the EM supplementation could improve the feed conversion efficiency and led to the decrease of FCR. These findings agree with previous studies regarding the beneficial effects of EM and probiotics on the growth performance and gut health of partridge shank broiler chicks (Chantsawang et al., 1999;

Safalaoh., 2006; Alkhalf et al., 2010; Xu et al., 2014; Fazelnia et al., 2021). Chantsawang et al. 
308 (1999) evaluated the effects of EM supplementation on 4 different types of poultry, and it was

309 found that EM additive could significantly increase breast percentage in Muscovy duck, and

310 decrease ash content of breast meat in Arbor Acers broiler chickens. Safalaoh et al. (2006)

311 demonstrated that the addition of EM in diet significantly increased BW gains $(2094 \pm 11 \mathrm{~g})$ and

312 ADG compared to broilers on the control diet (2057 $\pm 15 \mathrm{~g})$ during 1-42 days of age. However, on

313 the other hand, there are some reports which state that probiotics or EM had no role on the

314 growth performance and mortality in broilers. It has been found that the addition of probiotics or

315 prebiotics in broiler diet reduced feed intake (Mokhtari et al., 2010; Chen et al., 2015). Others

316 have demonstrated that the use of probiotics in broiler diet did not affect FCR (Sarangi et al.,

317 2016). In addition, it was found that the weight gain was not affected by supplementation of

318 probiotics (Yousefi et al., 2007). The inconsistent results of aforementioned studies might

319 attribute to multiple factors, including probiotic types and dose being used, and other potential

element(s) (Kabir., 2009; Sohail et al., 2012).

321 In this study, the EM addition positively influenced the histomorphological characteristics of

the broilers' intestine. Histological observation indicated the supplementation of EM increased

the height of intestinal villi in jejunum, ileum and cecum. The structure of intestinal villi were

covered with the intestinal epithelium, under which there was a continuous cell layer of

myofibroblasts that could regulate the epithelial renewal and defense processes (Ackermann et 
329

330

331

332

probiotics Saccharomyces boulardii and Bacillus cereus had beneficial effects on the epithelial structure and cryptic morphology (Baum et al., 2002). Awad et al. (2009) found that addition of probiotics composed of Lactobacillus salivarius and Lactobacillus reuteri in feed and found that probiotics significantly increased the $\mathrm{BW}$, average daily weight gain, and improved the villus integrity in small intestines, increased the $\mathrm{VH} / \mathrm{CD}$ ratio in duodenum in broilers. The EM used in this study contained multiple probiotic bacteria, such as Lactobacillus (abundance of $84 \% \pm 12 \%$, Table S1) and Bacillus $(0.09 \% \pm 0.11 \%)$, which might benefit the villus and cryptic morphology and then promote the intestinal health.

Probiotics were suitable for domestic animals, because they can inhibit the growth of pathogenic bacteria and promote the growth of beneficial bacteria by producing different metabolites and thus improve the gut microecological environment (Cummings and Kong, 2004; Attia et al., 2013; Sun et al., 2019). Similar results were observed in the present study. Although the abundances of Lactobacillus were reduced in the chicks as they got older, the abundance of Lactobacillus in EM-treated partridge shank broiler chicks were elevated when compared with that in non-EM-treated broiler chicks. The abundance of Acinetobacter was significantly lower in EM20 compared to that of B20. It is well known that most of the members of Acinetobacter enteropathogenic and can cause infections (Michalopoulos and Falagas, 2010). The commonly encountered pathogenic or zoonotic bacteria affecting birds, including E. coli, Streptococcus, and Clostridium were slightly reduced in the gut of EM-treated partridge shank broiler chicks. Together, the supplementation of EM in feed could ameliorate the community and structure of the intestinal microbiota of partridge shank broiler chicks. 
CONCLUSIONS

352 In this study, we observed that the feed supplemented with EM could increase the body weight

353 and average daily gain, and reduced feed conversion ratio, enhance intestinal integrity, and

354 balance the gut microflora of partridge shank broiler chicks. The findings might provide an

355 alternative to improve the growth performance and the gut health of partridge shank broiler

356 chicks.

357

358

359

360

361

362

363

364

365

366

367

368

369

370

371

372 read and agreed to the published version of the manuscript.

373

\section{ADDITIONAL INFORMATION AND DECLARATIONS}

\section{Funding}

This work was funded by the National Natural Science Foundation of China (31960711) and the Natural Science Foundation of Jiangxi Province (20202BABL215024). The founders had no role in the study design, sample collection, detection, sequencing, analysis and interpretation, or the manuscript preparation.

\section{Conflicts of Interest}

The authors declare that the research was conducted in the absence of any commercial or financial relationships that could be construed as a potential conflict of interest.

\section{Author Contributions}

The individual contributions in the present study were as follows: conceptualization and methodology D. S., and Y. T.; validation Z. Y., Z. L., and P. W.; Investigation: Z. Y., B. Z., M. Z., and D. H.; data duration Y. Y., Z. D., G. W., and Q. W.; writing-original draft preparation Z. Y., and Z. L.; project administration D. S., and Q. W.; funding acquisition D. S. All authors have

\section{Data availability statement}


375

376

377

378

379

380

381

382

383

384

385

386

387

388

389

390

391

392

393

394

395

396

397

398

399

400

401

402

403

404

405

406

407

All sample raw reads were deposited at the Short Reads Archive (SRA) database belongs to the

National Center for Biotechnology Information (NCBI) and are available under Bioproject ID

PRJNA629019.

Acknowledgments

We thank Prof. Nanhui Chen for providing the effective microorganism suspensions.

\section{REFERENCES}

Abd EM, El-Saadony MT, Shafi ME, Qattan S, Batiha GE, Khafaga AF, Abdel-Moneim AE, Alagawany M. 2020. Probiotics in poultry feed: A comprehensive review. Journal of Animal Physiology and Animal Nutrition (Berl) 104(6): 1835-1850. DOI: 10.1111/jpn.13454.

Ackermann J, Nowicki Z, Sarnecka-Keller M. 1974. Układ pokarmowy. Cytologia i histologia. (2nd ed.(345-422). Warsaw, PL: Pro-ed.

Ahmad S, Rehman R, Haider S, Batool Z, Ahmed F, Ahmed SB, Perveen T, Rafiq S, Sadir S, Shahzad S. 2018. Quantitative and qualitative assessment of additives present in broiler chicken feed and meat and their implications for human health. Journal of the Pakistan Medical Association 68(6):876-881.

Alagawany M, Abd EM, Farag MR, Sachan S, Karthik K, Dhama K. 2018. The use of probiotics as ecofriendly alternatives for antibiotics in poultry nutrition. Environmental science and pollution research international 25(11):10611-10618. DOI: 10.1007/s11356-018-1687-x

Alkhalf A, Alhaj M, Al-Homidan I. 2010. Influence of probiotic supplementation on blood parameters and growth performance in broiler chickens. Saudi Journal of Biological Sciences 17(3):219-225. DOI: 10.1016/j.sjbs.2010.04.005.

Alvarez LC, Barrera EM, Gonzalez EA. 1994. Evaluation of growth promoters for broiler chickens. Veterinaria Mexico, 25: 141-144.

Aruoma OI, Deiana M, Rosa A, Casu V, Piga R, Peccagnini S, Dessi MA, Ke B, Liang YF, Higa T. 2002. Assessment of the ability of the antioxidant cocktail-derived from fermentation of plants with effective microorganisms (EM-X) to modulate oxidative damage in the kidney and liver of rats in vivo: studies upon the profile of poly- and mono-unsaturated fatty acids. Toxicology Letters 135(3):209-217. DOI: 10.1016/s0378-4274(02)00261-8.

Attia YA, Abd HE, Ismaiel AM, El-Nagar A. 2013. The detoxication of nitrate by two antioxidants or a probiotic, and the effects on blood and seminal plasma profiles and reproductive function of New Zealand White rabbit bucks. Animal 7(4):591-601. DOI: 10.1017/S1751731112002054.

Award WA, Ghareeb K, Bohm J. 2009. Effect of addition of a probiotic micro-organism to broiler diet on intestinal mucosal architecture and electrophysiological parameters. J Anim Physiol Anim Nutr (Berl). 94(4):486-94. doi: 10.1111/j.1439-0396.2009.00933.x. 
408

409

410

411

412

413

414

415

416

417

418

419

420

421

422

423

424

425

426

427

428

429

430

431

432

433

434

435

436

437

438

439

440

441

442

443

444

Baum B, Liebler-Tenorio EM, Enss ML, Pohlenz JF, Breves G. 2002. Saccharomyces boulardii and Bacillus cereus var. toyoi influence the morphology and the mucins of the intestine of pigs. Zeitschrift fur Gastroenterologie, 40, 277-284. https://doi.org/10.1055/s-2002-30116

Chantsawang S, Watcharangkul P. 1999. Influence of effective micnoorganisms on the quality of poultry products. In:Proceedings of Intemationial Confierence on Kyusei Nature Farming :133-150.

Chen GO, Beski SSM, Choct M, Paul A. 2015. Novel probiotics: their effects on growth performance, gut development, microbial community and activity of broiler chickens. Anim. N. 1:184-191.

Cummings J, Kong S. 2004. Probiotics, prebiotics and antibiotics in inflammatory bowel disease. Novartis Found Symp 263:99-111, 111-114, 211-218.

Ergun A, Yalcin S, Sacakli P. 2000. The usage of probiotic and zinc bacitracin in broiler rations. Ankara Universities Veteriner Facultesi Dergisi, 47:271-280.

FAO W. 2002. Guidelines for the evaluation of probiotics in food. Report of a joint FAO/WHO working group on drafting guidelines for the evaluation of probiotics in food. London, Ontario, Canada.

Fazelnia K, Fakhraei J, Yarahmadi HM, Amini K. 2021. Dietary Supplementation of Potential Probiotics Bacillus subtilis, Bacillus licheniformis, and Saccharomyces cerevisiae and Synbiotic Improves Growth Performance and Immune Responses by Modulation in Intestinal System in Broiler Chicks Challenged with Salmonella Typhimurium. Probiotics Antimicrob Proteins.13(4):1081-1092. DOI: 10.1007/s12602-02009737-5.

Hack MEA,Saadony MT,Shafi ME,Qattan SYA, Batiha GE,Khafaga AF,Moneim AME,Alagawany M. 2020. Probiotics in poultry feed: A comprehensive review. Journal of Animal Physiology and Animal Nutrition, 104(6):1835-1850. DOI: 10.1111/jpn.13454.

Higa T. 1991. Effective microorganisms: A biotechnology for mankind.p. 8-14. In J.F. Parr, S.B. Hornick, and C.E. Whitman (ed.) Proceedings of the First International Conference on Kyusei Nature Farming. U.S. Department of Agriculture, Washington, D.C., USA

Huang C, Wang X, Liang C, Jiang X, Yong Q. 2019. A sustainable process for procuring biologically active fractions of high-purity xylooligosaccharides and water-soluble lignin from moso bamboo prehydrolyzate. Biotechnology for Biofuels, 12(1): 189. DOI: 10.1186/s13068-019-1527-3

Iriti M, Scarafoni A,Pierce S, Castorina G,Vitalini S. 2019. Soil Application of Effective Microorganisms (EM) Maintains Leaf Photosynthetic Efficiency, Increases Seed Yield and Quality Traits of Bean (Phaseolus vulgaris L.) Plants Grown on Different Substrates. Int J Mol Sci. 2019 May 10;20(9):2327.DOI: 10.3390/ijms20092327.

Jagdish P, Sen AK. 1993. Effect of different growth promoters on the performance of broilers. Poult Advisory, 26: 49-51.

Jha R, Das R, Oak S, Mishra P. 2020. Probiotics (Direct-Fed Microbials) in Poultry Nutrition and Their Effects on Nutrient Utilization, Growth and Laying Performance, and Gut Health: A Systematic Review. Animals (Basel) 10(10):1863. DOI: 10.3390/ani10101863.

Johnson TJ, Youmans BP, Noll S, Cardona C, Evans NP, Karnezos TP, Ngunjiri JM, Abundo MC, Lee 
CW. 2018. A Consistent and Predictable Commercial Broiler Chicken Bacterial Microbiota in AntibioticFree Production Displays Strong Correlations with Performance. Applied Environmeng Microbiology 84(12):e000362-18. DOI: 10.1128/AEM.00362-18.

Kabir SML. 2009. The Dynamics of probiotics in enhancing poultry meat production and quality. Department of Microbiology and Hygiene, Faculty of Veterinary science, Bangladesh Agricultural University. Int. J. Poult. Sci. 3:361-364.

Kuczynski J, Stombaugh J, Walters WA, Gonzalez A, Caporaso JG, Knight R. 2011. Using QIIME to analyze 16S rRNA gene sequences from microbial communities. Current Protocols in Bioinformatics Chapter 10:10-17. DOI: 10.1002/0471250953.bi1007s36.

Markowiak, P., Liewska, K. 2018. The role of probiotics, prebiotics and synbiotics in animal nutrition. Gut Pathogens, 10(1), 1-20. DOI: 10.1186/s13099-018-0250-0.

Li WJ, Ni YZ, Umemura H, Sun QL. 1994. Effect of EM on Crops and Animal Husbandry in China. Proceeding of 3rd Conference on EM Technology, 16-19th Nov, 1994

Manning TS, Gibson GR. 2004. Microbial-gut interactions in health and disease. Prebiotics. Best Practice \& Research: Clinical Gastroenterology, 18, 287-298. https://doi.org/10.1016/j.bpg.2003.10.008.

Mekbungwan A, Yamauchi K, Sakaida T. 2004. Intestinal villus histological alterations in piglets fed dietary charcoal powder including wood vinegar compound liquid. Anatomia Histologia Embryologia 33(1):11-16. DOI: 10.1111/j.1439-0264.2004.00501.x.

Michalopoulos A, Falagas ME. 2010. Treatment of Acinetobacter infections. Expert Opin Pharmacother 11(5):779-788. DOI: $10.1517 / 14656561003596350$.

Mokhtari R, Yazdani AR, Rezaei M, Ghorbani B. 2010. The effect of different growth promoters on performance and carcass characteristics of broiler chickens. J. Anim. Vet. Adv. 9:2633-2639.

Mount DW. 2007. Using the Basic Local Alignment Search Tool (BLAST). CSH Protocol:17. DOI: 10.1101/pdb.top17.

Patidar SK, Prajapati JB. 1999. Effect of feeding lactobacilli on serum antibody titer and faecal microflora in chicks. MICROBIOLOGIE ALIMENTS NUTRITION. 17(2):145-154.

Patterson JA, Burkholder KM. 2003. Application of prebiotics and probiotics in poultry production. Poultry Science 82(4):627-631. DOI: $10.1093 / \mathrm{ps} / 82.4 .627$.

Qorbanpour M, Fahim T, Javandel F, Nosrati M, Paz E, Seidavi A, Ragni M, Laudadio V, Tufarelli V. 2018. Effect of Dietary Ginger (Zingiber officinale Roscoe) and Multi-Strain Probiotic on Growth and Carcass Traits, Blood Biochemistry, Immune Responses and Intestinal Microflora in Broiler Chickens. Animals (Basel) 8(7):117. DOI: 10.3390/ani8070117.

Quast C, Pruesse E, Yilmaz P, Gerken J, Schweer T, Yarza P, Peplies J, Glockner FO. 2013. The SILVA ribosomal RNA gene database project: improved data processing and web-based tools. Nucleic Acids Research 41(Database issue):D590-6. DOI: 10.1093/nar/gks1219.

Quinn GP, K. M. ( 2002). Experimental Design and Data Analysis for Biologists, Cambridge University Press. 
481

482

483

484

485

486

487

488

489

490

491

492

493

494

495

496

497

498

499

500

501

502

503

504

505

506

507

508

509

510

511

512

513

514

515

516

Rehman A, Arif M, Sajjad N, Al-Ghadi MQ, Alagawany M, Abd EM, Alhimaidi AR, EInesr SS, Almutairi BO, Amran RA, Hussein E, Swelum AA. 2020. Dietary effect of probiotics and prebiotics on broiler performance, carcass, and immunity. Poultry Science 99(12):6946-6953. DOI: 10.1016/j.psj.2020.09.043.

Reszka P, Dunislawska A, Slawinska A, Kapelanski W, Bogucka J. 2020. Influence of the effective microorganisms (EM) on performance, intestinal morphology and gene expression in the jejunal mucosa of pigs fed different diets. J Anim Physiol Anim Nutr. 104: 1444-1453. DOI:10.1111/jpn.13404.

\section{Robinson K, Xiao YP, Johnson TJ, Chen BY, Yang Q, Lyu WT, Wang J, Fansler N, Becker S, Liu J,} Yang H, Zhang GL. 2020. Chicken Intestinal Mycobiome: Initial Characterization and Its Response to Bacitracin Methylene Disalicylate. Applied Environment Microbiolgy 86(13): e00304-20. DOI: 10.1128/AEM.00304-20

Rognes T, Flouri T, Nichols B, Quince C, Mahe F. 2016. VSEARCH: a versatile open source tool for metagenomics. PeerJ 4:e2584. DOI: 10.7717/peerj.2584.

Rybarczyk A, Romanowski M, Karamucki T, Ligocki M. 2016. The effect of Bokashi probiotic on pig carcass characteristics and meat quality. Fleischwirtschaft, 31:74-77.

Safalaoh ACL. 2006. Body weight gain, dressing percentage, abdominal fat and serum cholesterol of broilers supplemented with a microbial preparation. Afr. On Line J. Food, Agric. Nutr. Dev., 6: 1-10. DOI: 10.4314/ajfand.v6i1.19170

Sarangi NR, Babu LK, Kumar A, Pradhan CR, Pati PK, Mishra JP. 2016. Effect of dietary supplementation of prebiotic, probiotic, and synbiotic on growth performance and carcass characteristics of broiler chickens. Veterinary World 9(3):313-9. DOI: 10.14202/vetworld.2016.313-319.

Segata N, Izard J, Waldron L, Gevers D, Miropolsky L, Garrett WS, Huttenhower C. 2011. Metagenomic biomarker discovery and explanation. Genome Biology 12(6):R60. DOI: 10.1186/gb-201112-6-r60.

Silva EN, Teixeira AS, Bertechini AG, Ferreira CL, Ventura BG. 2000. Ciencia e Agrotecnologia. 24: Ed. Especial, 224-232.

Sohail MU, Hume ME, Byrd JA, Nisbet DJ, Ijaz A, Sohail A, Shabbir MZ, Rehman H. 2012. Effect of supplementation of prebiotic mannan-oligosaccharides and probiotic mixture on growth performance of broilers subjected to chronic heat stress. Poultry Science 91(9): 2235-40. DOI: 10.3382/ps.2012-02182.

Song DP, Peng Q, Chen YJ, Zhou XR, Zhang FF, Li AQ, Huang DY, Wu Q, Ye Y, He HJ, Wang LY, Tang YX. 2017. Altered Gut Microbiota Profiles in Sows and Neonatal Piglets Associated with Porcine Epidemic Diarrhea Virus Infection. Scientific Reports 7(1):17439. DOI: 10.1038/s41598-017-17830-z.

Soomro RN, Abd EM, Shah SS, Taha AE, Alagawany M, Swelum AA, Hussein E, Ba-Aawdh HA, Saadeldin I, EI-Edel MA, Tufarelli V. 2019. Impact of restricting feed and probiotic supplementation on growth performance, mortality and carcass traits of meat-type quails. Animal Science Journal 90(10):13881395. DOI: $10.1111 /$ asj.13290.

PeerJ reviewing PDF | (2021:06:62818:3:0:NEW 25 Oct 2021) 
517

518

519

520

521

522

523

524

525

526

527

528

529

530

531

532

533

534

535

536

537

538

539

540

541

542

543

544

545

546

547

Sun P, Zhang W, Miao Y, Chen Z. 2019. Letter: meta-analysis of prebiotics, probiotics, synbiotics and antibiotics in IBS. Alimentary Pharmacology and Therrapeutics 49(9):1253-1254. DOI: 10.1111/apt.15234.

Tao Y, Wang T , Huang C, Lai C, Zhe L, Zhou Y, Qiang Y. 2021. Production performance, egg quality, plasma biochemical constituents and lipid metabolites of aged laying hens supplemented with incomplete degradation products of galactomannan. Poultry Science, 2021, 100( 8): 101296. DOI: 10.1016/j.psj.2021.101296

Vicente JL, AviãfâA L, Rodriguez AT, Hargis B, Tellez G. 2007. Effect of a Lactobacillus Spp-Based Probiotic Culture Product on Broiler Chicks Performance under Commercial Conditions. International Journal of Poultry Science, 6(3). DOI: 10.3923/ijps.2007.154.156.

Vinayasree C, Reddy KK, Gupta PSP, Reddy PVM, Nagalakshmi D. 2012. Evaluation of probiotic organisms on performance of broilers. The Indian veterinary journal, 89(7):16-19.

Waititu SM, Yitbarek A, Matini E, Echeverry H, Kiarie E, Rodriguez-Lecompte JC, Nyachoti CM. 2014. Effect of supplementing direct-fed microbials on broiler performance, nutrient digestibilities, and immune responses. Poultry Science 93(3):625-635. DOI: 10.3382/ps.2013-03575.

Wondmeneh E, Getachew TT, Dessie T. 2011. Effect of Effective Microorganisms (EM) on the Growth Parameters of Fayoumi and Horro Chicken. International Journal of Poultry Science 3(10):185-188. DOI:10.3923/ijps.2011.185.188

Xu, QQ, Yan H, Liu XL, Lv L, Yin CH, Wang P. 2014. Growth performance and meat quality of broiler chickens supplemented with Rhodopseudomonas palustris in drinking water. British Journal of Poultry Science 55(3):360-6. DOI: 10.1080/00071668.2014.903326.

Yousefi M, Karkoodi K. 2007. Effect of probiotic Thepax and Saccharomyces cerevisiae supplementation on performance and egg quality of laying hens. Int. J. Poult. Sci. 6:52-54.

Zhang YH, Chen YJ, Yuan WF, Peng Q, Zhang FF, Ye Y, Huang DH, Ding Zhen, Lin LH, He HJ, Wu Q, Song DP, Tang YX. 2020. Evaluation of Cross-Protection between G1a- and G2a-Genotype Porcine Epidemic Diarrhea Viruses in Suckling Piglets. Animals, 10, 1674. DOI: 10.3390/ani10091674.

Zhao, YR., Chen YP, Cheng YF, Qu HM, Li J, Wen C, Zhou YM. 2019. Effects of dietary phytosterols on growth performance, antioxidant status, and meat quality in Partridge Shank chickens. Poultry Science 98(9):3715-3721. DOI: 10.3382/ps/pez059.

Zuanon JAS , Fonseca JB , Rostagno HS. Silva MDA, 1998. Effects of growth promoters on broiler chickens performance. Revista Brasileira De Zootecnia,27(5):999-1005. DOI:10.1016/S0301-6226 (98)00137-7. 
Figure 1

Figure 1. Principal component analysis ( $\mathrm{PCOA}$ ) based on the sequences from all samples tested (A), excreta samples from the 0 (B), 10th (C), and 20th (D) experimental day, and cecal content samples from the 20th experimental day (E).
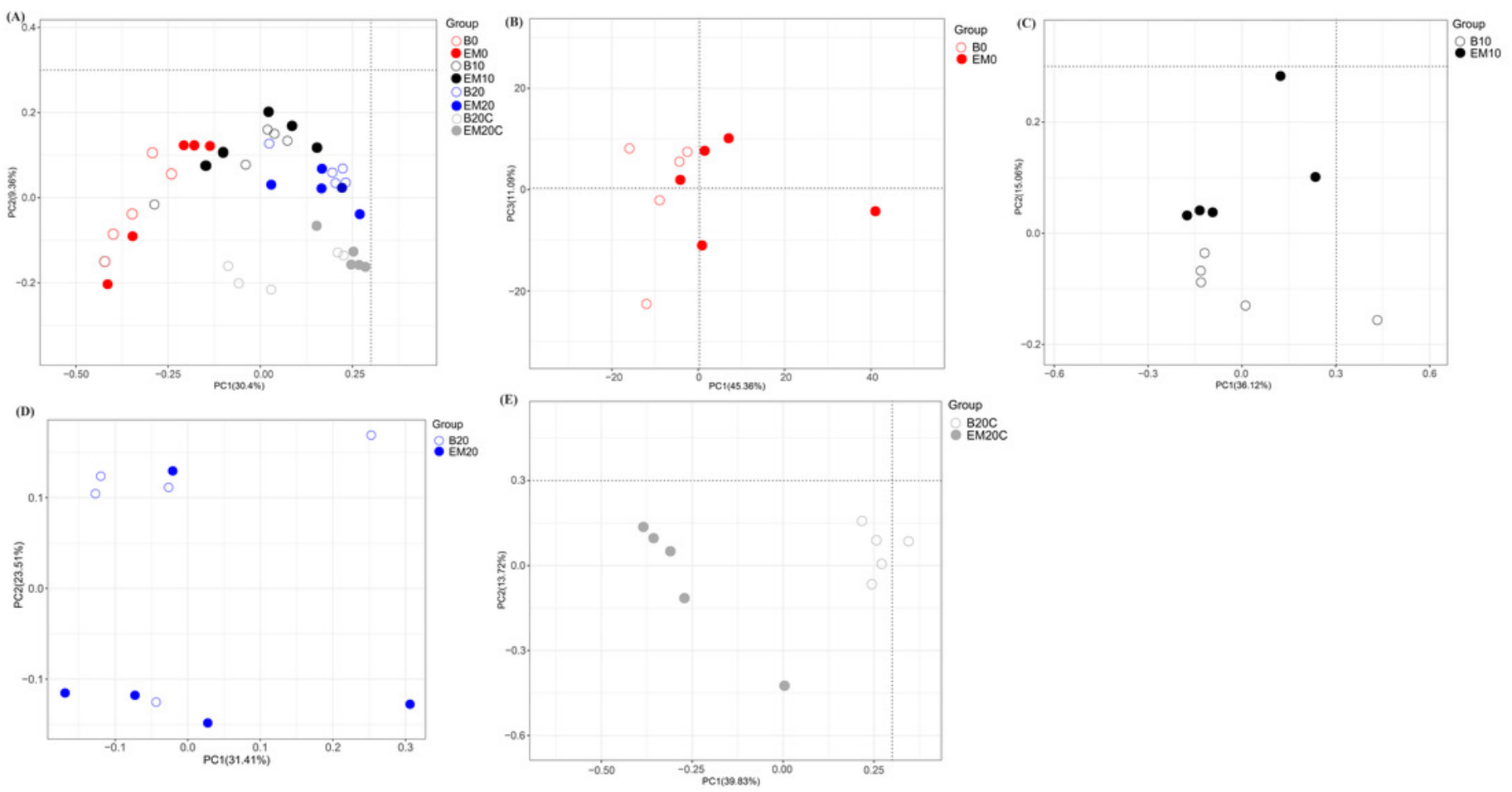


\section{Figure 2}

Figure 2. Gut microbial composition at phylum-level.

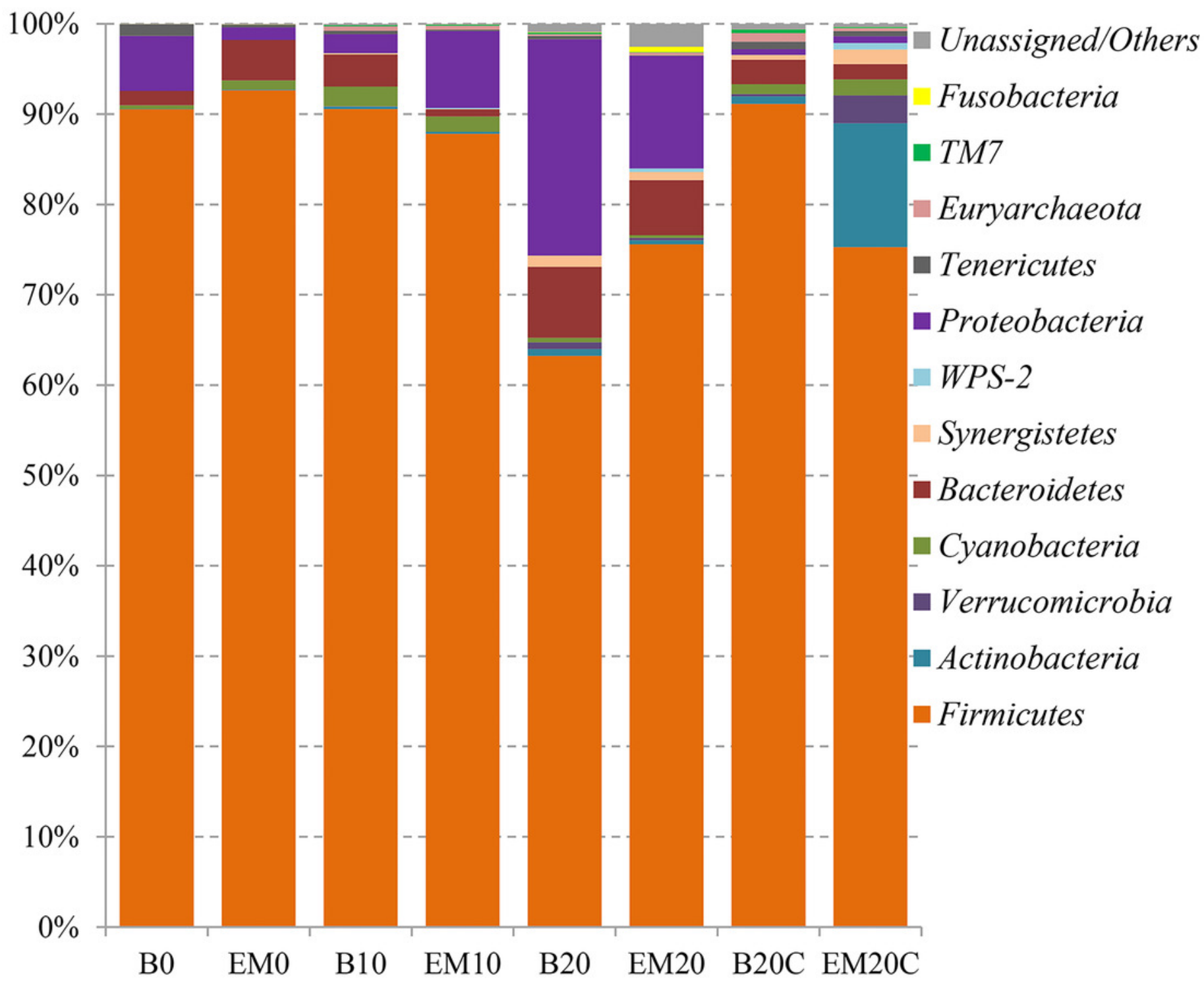




\section{Figure 3}

Figure 3. Gut microbial composition at genus-level.

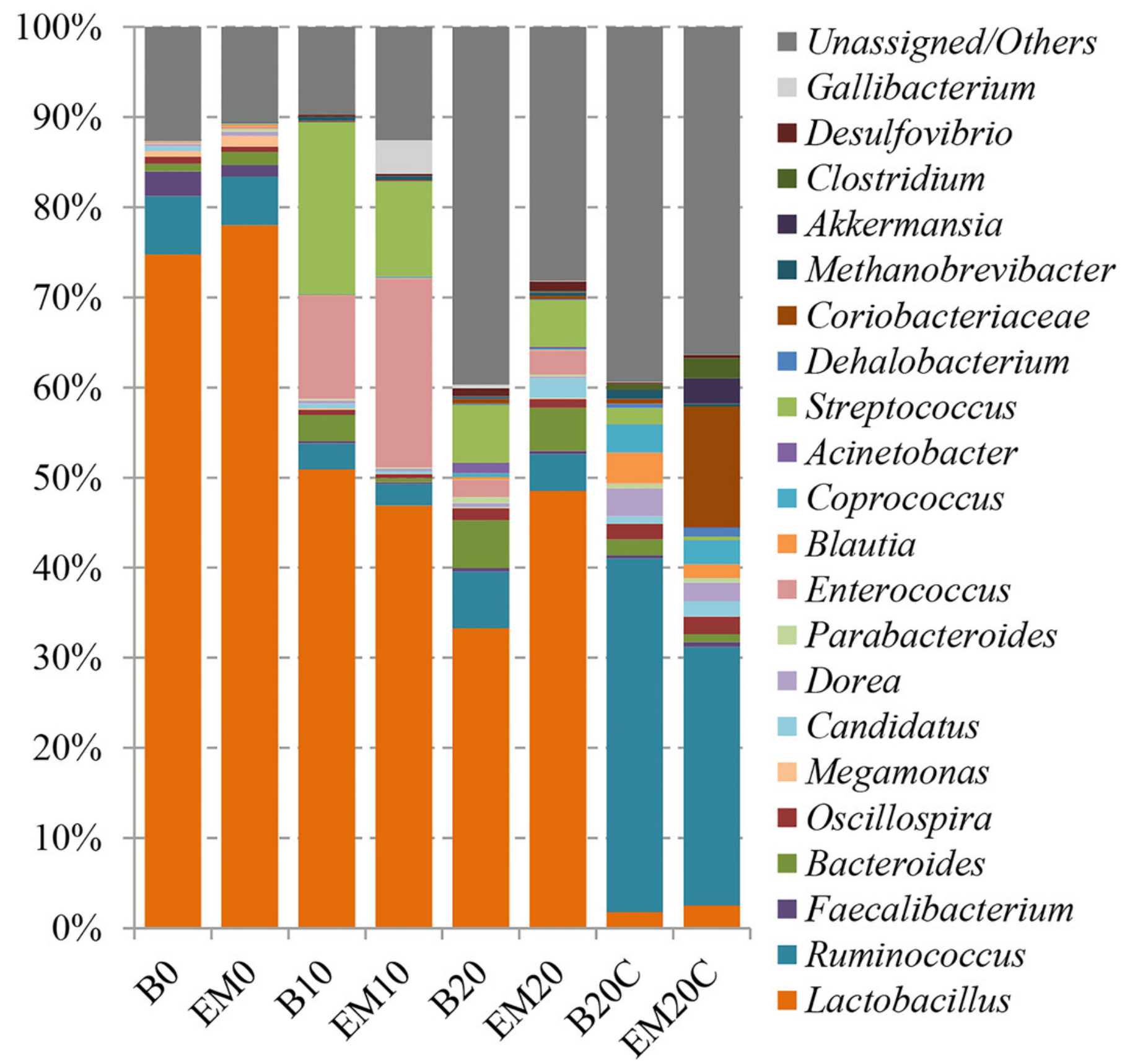


Table $\mathbf{1}$ (on next page)

Tables 
1 Article

2 Effects of probiotic supplements on growth performance and

3 intestinal microbiota of partridge shank broiler chicks

4 Yizhe Ye ${ }^{1,2, \dagger}$, Zhiquan $\mathrm{Li}^{1,2, \dagger}$, Ping Wang1, ${ }^{1,}$, Bin Zhu ${ }^{3}$, Min Zhao ${ }^{1,2}$, Dongyan Huang ${ }^{1,2}$,

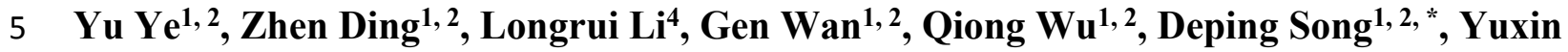

6 Tang 1,2

7

8 Tables and Figures

9

10

11

12

13

14

15

16

17 
18 Tables

19

20

Table 1 Ingredient composition of the basal diet being fed for the broiler chickens used in this study

\begin{tabular}{ll}
\hline Item & Amount $(\mathrm{g} / \mathrm{kg})$ \\
\hline Ingredients & 581.5 \\
Corn meal & 335 \\
Soybean meal & 32.1 \\
Soybean oil & 13 \\
Limestone & 20.5 \\
Dicalcium phosphate & 3.4 \\
L-lysine & 1.5 \\
DL-Methionine & 3 \\
Sodium chloride & 10 \\
Premix &
\end{tabular}

Calculated nutrient levels

Metabolizable energy (MJ/kg DM) $\quad 12.08$

Crude protein (g/kg DM) 19.25

Calcium (g/kg DM) 1.07

Available phosphorus (g/kg DM) 4.6

Lysine (g/kg DM) 12.6

$\begin{array}{ll}\text { Methionine (g/kg DM) } & 4.27\end{array}$

Methionine + cysteine (g/kg DM) $\quad 8.35$

DM: dry matter; Premix provided per kilogram of diet: vitamin A (all-trans-retinyl acetate), 10,000 IU; vitamin D3 (cholecalciferol), 3,000 IU; vitamin E (all-rac- $\alpha$-tocopherol), $30 \mathrm{IU}$; menadione, $1.3 \mathrm{mg}$; thiamin, $2.2 \mathrm{mg}$; riboflavin, $8 \mathrm{mg}$; nicotinamide, $40 \mathrm{mg}$; choline chloride, 400 mg; calcium pantothenate, $10 \mathrm{mg}$; pyridoxine $\cdot \mathrm{HCl}, 4 \mathrm{mg}$; biotin, $0.04 \mathrm{mg}$; folic acid, $1 \mathrm{mg}$; vitamin B12 (cobalamin), $0.013 \mathrm{mg}$; Fe (from ferrous sulphate), $80 \mathrm{mg}$; $\mathrm{Cu}$ (from copper sulphate), $8.0 \mathrm{mg}$; $\mathrm{Mn}$ (from manganese sulphate), $110 \mathrm{mg}$; $\mathrm{Zn}$ (from zinc oxide), $60 \mathrm{mg}$; I (from calcium iodate), $1.1 \mathrm{mg}$; Se (from sodium selenite), $0.3 \mathrm{mg}$. 

with or without EM

\begin{tabular}{|c|c|c|c|}
\hline Item & EM-treated boilers & Non-EM treated boilers & p-value (ANOVA) \\
\hline \multicolumn{4}{|l|}{$\mathrm{BW}, \mathrm{g}$} \\
\hline 1 day & $145.70 \pm 6.68$ & $146.10 \pm 5.28$ & 0.846 \\
\hline 10th day & $274.30 \pm 10.80$ & $254.60 \pm 12.52$ & $0.001^{* *}$ \\
\hline 20th day & $563.40 \pm 32.22$ & $533.10 \pm 19.55$ & $0.020^{*}$ \\
\hline \multicolumn{4}{|l|}{ ADFI, g/day } \\
\hline $1-10$ days & $36.49 \pm 8.54$ & $35.47 \pm 6.51$ & 0.766 \\
\hline 11-20 days & $56.74 \pm 7.58$ & $53.39 \pm 7.07$ & 0.321 \\
\hline $1-20$ days & $46.62 \pm 13.02$ & $44.43 \pm 11.32$ & 0.574 \\
\hline \multicolumn{4}{|l|}{ ADG, g/day } \\
\hline 1-10 days & $12.86 \pm 1.27$ & $10.85 \pm 1.07$ & $0.001^{* *}$ \\
\hline 11-20 days & $28.91 \pm 3.03$ & $27.85 \pm 1.85$ & $0.048^{*}$ \\
\hline 1-20 days & $20.89 \pm 3.38$ & $19.33 \pm 2.04$ & $0.025^{*}$ \\
\hline \multicolumn{4}{|l|}{ FCR } \\
\hline $1-10$ days & 2.84 & 3.27 & $0.021^{*}$ \\
\hline 11-20 days & 1.96 & 1.92 & $0.049^{*}$ \\
\hline 1-20 days & 2.40 & 2.59 & 0.053 \\
\hline
\end{tabular}

$\mathrm{BW}=$ body weight; $\mathrm{AVG}=$ average; $\mathrm{SD}=\mathrm{Standard}$ deviation; $\mathrm{ADFI}=$ average daily feed intake; $\mathrm{ADG}=$ average daily gain; $\mathrm{FCR}=$ feed conversion ratio. $*$ indicates $0.01<\mathrm{p}$ value $<0.05, * *$ indicates $0.01<\mathrm{p}$ value $<0.001$. 
41 Table 3 The villus height and crypt depth of intestine in chickens between EM-treated and 42 non-EM-treated negative control groups

\begin{tabular}{|c|c|c|c|c|}
\hline \multirow{2}{*}{ Item } & \multirow{2}{*}{$\begin{array}{c}\text { Intestinal } \\
\text { section }\end{array}$} & \multicolumn{2}{|c|}{ Average length \pm standard deviation, $\mu \mathrm{m}$} & \multirow{2}{*}{$\begin{array}{c}\mathrm{p} \text {-value } \\
\text { (ANOVA) }\end{array}$} \\
\hline & & EM-treated & Control & \\
\hline \multirow{3}{*}{$\begin{array}{l}\text { Villus } \\
\text { height } \\
(\mathrm{VH})\end{array}$} & Jejunum & $575.35 \pm 59.28$ & $427.28 \pm 52.80$ & $0.000^{* * *}$ \\
\hline & Ileum & $520.13 \pm 42.93$ & $342.79 \pm 22.47$ & $0.000^{* * *}$ \\
\hline & Cecum & $82.83 \pm 17.32$ & $50.44 \pm 9.27$ & $0.000^{* * *}$ \\
\hline \multirow{3}{*}{$\begin{array}{l}\text { Crypt } \\
\text { depth } \\
\text { (CD) }\end{array}$} & Jejunum & $39.55 \pm 10.46$ & $52.42 \pm 11.88$ & $0.001^{* *}$ \\
\hline & Ileum & $35.06 \pm 10.14$ & $42.03 \pm 9.88$ & $0.034^{*}$ \\
\hline & Cecum & $19.01 \pm 2.91$ & $22.42 \pm 4.86$ & $0.011^{*}$ \\
\hline \multirow{3}{*}{$\begin{array}{c}\text { VH/CD } \\
\text { value }\end{array}$} & Jejunum & $15.45 \pm 4.12$ & $8.51 \pm 2.06$ & $0.000^{* * *}$ \\
\hline & Ileum & $16.16 \pm 5.69$ & $8.64 \pm 2.30$ & $0.000^{* * *}$ \\
\hline & Cecum & $4.46 \pm 1.14$ & $2.39 \pm 0.79$ & $0.000^{* * *}$ \\
\hline
\end{tabular}

43 Note: $*$ indicates $0.01<\mathrm{p}$ value $<0.05, * *$ indicates $0.001<\mathrm{p}$ value $<0.01, * * *$ indicates $\mathrm{p}$ value $<0.001$.

Table 4 Microbiota alpha diversity among groups of chickens by Kruskal-Walls test

\begin{tabular}{cccccc}
\hline Group & Shannon & Simpson & Chao1 & Ace & Goods_coverage \\
\hline B0 & $3.41 \pm 1.33$ & $0.696 \pm 0.26$ & $392.94 \pm 110.63$ & $383.08 \pm 110.63$ & $1.00 \pm 0.00$ \\
EM0 & $3.57 \pm 0.96$ & $0.76 \pm 0.12$ & $433.23 \pm 188.59$ & $433.07 \pm 186.16$ & $1.00 \pm 0.00$ \\
p-value & 0.83 & 1.00 & 0.69 & 0.62 & 1.00 \\
\cline { 2 - 6 } B10 & $3.51 \pm 1.09$ & $0.74 \pm 0.10$ & $538.89 \pm 209.50$ & $536.24 \pm 203.14$ & $1.00 \pm 0.00$ \\
EM10 & $3.17 \pm 1.44$ & $0.69 \pm 0.25$ & $584.54 \pm 201.78$ & $563.80 \pm 198.39$ & $1.00 \pm 0.00$ \\
p-value & 0.69 & 1.00 & 0.69 & 0.83 & 1.00 \\
\cline { 2 - 6 } B20 & $4.86 \pm 1.89$ & $0.84 \pm 0.17$ & $899.23 \pm 201.02$ & $897.80 \pm 190.29$ & $1.00 \pm 0.00$ \\
EM20 & $4.36 \pm 1.51$ & $0.86 \pm 0.08$ & $857.33 \pm 247.88$ & $853.84 \pm 250.80$ & $1.00 \pm 0.00$ \\
p-value & 0.55 & 1.00 & 0.84 & 0.76 & 1.00 \\
\cline { 2 - 6 } B20C & $6.56 \pm 0.42$ & $0.96 \pm 0.02$ & $697.89 \pm 398.22$ & $689.15 \pm 388.87$ & $1.00 \pm 0.00$ \\
EM20C & $6.41 \pm 0.63$ & $0.96 \pm 0.03$ & $1061.42 \pm 163.78$ & $1054.42 \pm 159.89$ & $1.00 \pm 0.00$ \\
p-value & 1.00 & 0.84 & 0.15 & 0.09 & 1.00 \\
\hline
\end{tabular}


47 Table 5 Abundance differences of bacteria among the bird gut in non-EM-treated negative 48 control group

\begin{tabular}{cccccc}
\hline \multirow{2}{*}{ Bacterial name } & \multicolumn{3}{c}{ Average abundance, $\%$} & $\begin{array}{c}\text { ANOVA } \\
\text { test } \mathrm{p} \\
\text { value }\end{array}$ & Significance \\
\cline { 2 - 5 } Firmicutes & $\mathrm{B} 0$ & $\mathrm{~B} 10$ & $\mathrm{~B} 20$ & 0.032 & $* * *$ \\
Euryarchaeota & 0.0003 & 0.5090 & 0.1959 & 0.000 & $* * *$ \\
Synergistetes & 0.0000 & 0.1370 & 1.2271 & 0.000 & $* * *$ \\
Verrucomicrobia & 0.0001 & 0.0222 & 0.7400 & 0.000 & $* * *$ \\
Actinobacteria & 0.0000 & 0.0003 & 0.0008 & 0.005 & $* * *$ \\
Methanobrevibacter & 0.0003 & 0.4394 & 0.1830 & 0.000 & $* * *$ \\
Prevotella & 0.0045 & 0.0701 & 0.2755 & 0.000 & $* * *$ \\
Streptococcus & 0.0116 & 19.0748 & 6.4261 & 0.000 & $* * *$ \\
Coprococcus & 0.0383 & 0.0906 & 0.4035 & 0.000 & $* * *$ \\
Desulfovibrio & 0.0056 & 0.0047 & 0.0640 & 0.000 & $* * *$ \\
Gallibacterium & 0.0000 & 0.0128 & 0.3822 & 0.000 & $* * *$ \\
Acinetobacter & 0.0252 & 0.0022 & 1.1387 & 0.000 & $* * *$ \\
\hline
\end{tabular}

49

Table 6 Abundance differences of bacteria among the gut of EM-treated broiler chickens

\begin{tabular}{cccccc}
\hline \multirow{2}{*}{ Bacterial name } & \multicolumn{3}{c}{ Average abundance, $\%$} & $\begin{array}{c}\text { Variation } \\
\text { test p } \\
\text { value }\end{array}$ & Significance \\
\cline { 2 - 5 } EM0 & EM10 & EM20 & & $*$ * \\
Euryarchaeota & 0.0001 & 0.4001 & 0.3005 & 0.0000 & $* *$ \\
Proteobacteria & 1.4001 & 8.5000 & 12.4002 & 0.0040 & $* * *$ \\
Synergistetes & 0.0000 & 0.0002 & 0.9000 & 0.0000 & $* * *$ \\
WPS-2 & 0.0000 & 0.1000 & 0.4002 & 0.0000 & $* * *$ \\
Methanobrevibacter & 0.0000 & 0.4000 & 0.3000 & 0.0000 & $* * *$ \\
Enterococcus & 0.3001 & 20.9002 & 2.6001 & 0.0000 & $* * *$ \\
Streptococcus & 0.0001 & 10.5001 & 5.2003 & 0.0000 & $* * *$ \\
Faecalibacterium & 1.3000 & 0.2000 & 0.3000 & 0.6070 & NA \\
Megamonas & 1.2001 & 0.0001 & 0.1001 & 0.0000 & $* * *$ \\
\hline
\end{tabular}




\begin{tabular}{cccccc}
\hline Desulfovibrio & 0.0001 & 0.3000 & 1.0000 & 0.0000 & $* * *$ \\
Gallibacterium & 0.0000 & 3.7000 & 0.1000 & 0.0000 & $* * *$ \\
\hline
\end{tabular}

51 Table 7 Abundance differences of bacteria in feces between EM-treated and non-EM-

52 treated negative control Partridge Shank broiler chickens

\begin{tabular}{ccccc}
\hline \multirow{2}{*}{ Bacterial name } & \multicolumn{2}{c}{ Average abundance, \% } & Variation test & Significance \\
\cline { 2 - 3 } & $\mathrm{B} 20$ & $\mathrm{EM} 20$ & $\mathrm{p}$ value & ** \\
\hline TM7 & 0.2001 & 0.0000 & 0.0021 & $* *$ \\
Tenericutes & 0.4001 & 0.1002 & 0.0021 & $*$ \\
Acinetobacter & 1.1000 & 0.2000 & 0.0350 & $*$ \\
\hline
\end{tabular}

53

Table 8 Abundance differences of bacteria in cecal contents between EM-treated and nonEM-treated negative control Partridge Shank broiler chickens

\begin{tabular}{ccccc}
\hline \multirow{2}{*}{ Bacterial name } & \multicolumn{2}{c}{ Average abundance, $\%$} & Variation test \\
\cline { 2 - 4 } & $\mathrm{B} 20 \mathrm{C}$ & $\mathrm{EM} 20 \mathrm{C}$ & $\mathrm{p}$ value & Significance \\
\hline Euryarchaeota & 1.0003 & 0.3001 & 0.0431 & $*$ \\
Actinobacteria & 0.8001 & 13.7001 & 0.0000 & $* * *$ \\
Firmicutes & 91.1000 & 75.3000 & 0.0051 & $* *$ \\
WPS-2 & 0.0002 & 0.7001 & 0.0000 & $* * *$ \\
Ruminococcus & 15.8001 & 4.1001 & 0.0350 & $*$ \\
\hline
\end{tabular}




\section{Figure Legends}

Figure 1. Principal component analysis (PCoA) based on the sequences from all samples tested (A), excreta samples from the 0 (B), 10th (C), and 20th (D) experimental day, and cecal content samples from the 20th experimental day (E).

Figure 2. Gut microbial composition at phylum-level.

Figure 3. Gut microbial composition at genus-level.

\section{Supporting Tables}

Table S1 Construction of EM used in this study.

Table S2 Summary of sequencing data obtained in this study.

Table S3 Abundances of intestinal flora between EM-treated and control group at the phylum level.

Table S4 Abundance table of intestinal flora between EM-treated and control groups at the genus level.

\section{Supporting Figures}

Figure S1 Excretal Bacteria with significant abundances among the bird gut in non-EMtreated negative control group at phylum (A) and genus (B) level.

Figure S2 Excretal Bacteria with significant abundances among the bird gut in EM-treated 
negative control group at phylum (A) and genus (B) level.

Figure S3 Excretal Bacteria with significant abundances between the EM-treated and non-

EM treated broilers at phylum (A) and genus (B) level.

Figure S4 Cecal Bacteria with significant abundances between the EM-treated and non-

EM treated broilers at phylum (A) and genus (B) level. 